\title{
Women Who Develop Diabetes Later in Life Have Diabetes-Associated Complications during Preceding Pregnancies
}

\author{
Ulrika Moll1,2, Håkan Olsson1,3, Mona Landin-Olsson1,2* \\ ${ }^{1}$ Department of Clinical Science, Lund University, Lund, Sweden \\ ${ }^{2}$ Department of Endocrinology, Skane University Hospital, Lund, Sweden \\ ${ }^{3}$ Department of Oncology, Skane University Hospital, Lund, Sweden \\ Email: Ulrika.moll@med.lu.se, hakan.olsson@med.lu.se, ${ }^{*}$ mona.Landin-Olsson@med.lu.se
}

Received 27 August 2014; revised 25 September 2014; accepted 20 October 2014

Academic Editor: Sharma S. Prabhakar, Texas Tech University Health Sciences Center, USA

Copyright (C) 2014 by authors and Scientific Research Publishing Inc.

This work is licensed under the Creative Commons Attribution International License (CC BY).

http://creativecommons.org/licenses/by/4.0/

(c) (i) Open Access

\begin{abstract}
Aims: The aim of this study was to explore the outcome of previous pregnancies in women who later developed diabetes. Method: A Swedish population based cohort of 23,524 women from 1990 aged 45 - 85 yr in 2000 when they self reported health status in a questionnaire. To identify which women who delivered we matched it towards the Swedish Medical Birth Register (SMBR). We identified 14,856 women who appeared in both registers and a total of 30,559 new birth registrations. Among these women 216 had developed diabetes after their pregnancy (ies) and additional twelve women were reported to have gestational diabetes in SMBR. These 228 women and their 455 pregnancies were compared with women without diabetes. Results: Women who developed diabetes later in life were already heavier before the pregnancy (ies) $(69.2 \pm 13.9$ vs. $63.2 \pm 10.3$ $\mathrm{kg} ; \mathrm{p}<0.001)$ but had less weight gain during pregnancy $(13.3 \pm 5.4 \mathrm{vs.} 14.1 \pm 4.6 \mathrm{~kg} ; \mathrm{p}=0.03)$ compared to women without diabetes. Newborns to women with diabetes diagnosed any time after pregnancy had higher birth weight $(3602 \mathrm{vs.} 3507 \mathrm{~g}$; $<$ 0.001), were more often large for gestational age $(10.5 \%$ vs. $3.1 \% ; p<0.001)$, were more often delivered by caesarean section $(4.8 \%$ vs. 2.7\%; $p=0.005$ ) and had lower Apgar scores. Conclusion: Women who developed diabetes after pregnancy had hyperglycaemia-associated complications during their pregnancy (ies). We therefore postulated that women with Type 2 diabetes are mainly recruited from women with earlier GDM. A general screening for GDM should identify these women and enable life style intervention that may prevent or at least delay diabetes.
\end{abstract}

\footnotetext{
*Corresponding author.
}

How to cite this paper: Moll, U., Olsson, H. and Landin-Olsson, M. (2014) Women Who Develop Diabetes Later in Life Have Diabetes-Associated Complications during Preceding Pregnancies. Journal of Diabetes Mellitus, 4, 341-349. 


\section{Keywords}

\section{Gestational Diabetes, Type 2 Diabetes, Pregnancy Outcome, Prenatal Care, Retrospective Study, Fetal Macrosomia, Large for Gestational Age, Prediabetes}

\section{Introduction}

During pregnancy there is an increased demand on the beta cells that can unmask incipient type 2 diabetes and be expressed as gestational diabetes (GDM), transient glucose intolerance during pregnancy. Later in life 3\% $41 \%$ of the women with previous GDM will develop type 2 diabetes [1] [2]. The large variation in manifestation of type 2 diabetes following GDM in the different studies is partly due to different time of follow-up, difference in ethnicity, differences in diagnostic criteria and screening procedures. In a Danish study, two thirds of women with GDM had an abnormal glucose metabolism after long term follow-up and the risk for diabetes in the offspring was 8-fold [3].

Hyperglycaemia, independent on whether the patient has Type 1, Type 2 or gestational diabetes, during pregnancy is a risk factor for both mother and child. For the mother there is an increased risk of pre-eclampsia, nephropathy, preterm labour, birth trauma and caesarean section and for the infant risk of malformations, macrosomia, shoulder dystocia, postnatal hypoglycaemia and stillbirth [4] [5].

After 1995 all pregnant women in our region are screened by Oral Glucose Tolerance Test (OGTT) with 75 g glucose, using 2-h capillary-P-Glucose of $10.0 \mathrm{mmol} / \mathrm{L}(180 \mathrm{mg} / \mathrm{dL})$ as cut off level. The reported frequency of GDM is $1.2 \%$ - $1.9 \%$ [6] [7]. With 2-h capillary-P-glucose value $8.6-10.0 \mathrm{mmol} / \mathrm{L}(155-180 \mathrm{mg} / \mathrm{dL})$, there is also an increased risk of caesarean section and macrosomia [6] [8]. The lower limit of $8.5 \mathrm{mmol} / \mathrm{l}$ has been applied in the GDM criteria stated by International Association of Diabetes in Pregnancy Study Groups (IADPSG), due to experienced adverse effects seen at these glucose levels [9].

There is a strong association between the degree of hyperglycaemia and the risk of infants who are large for gestational age (LGA) and/or caesarean section [10]-[12]. Studies have shown a reduced perinatal morbidity and mortality if GDM is treated towards glucose levels below cut-off point for diabetes [13]. Intervention also of mild hyperglycaemia during pregnancy reduces birth weight of the infants, frequency of LGA-births and macrosomic births and caesarean sections [14]. A metaanalysis concluded that treatment of GDM lowered the risk of perinatal complications, such as shoulder dystocia and pre-eclampsia and reduced risk of giving birth to LGAinfants [15].

There is still no consensus for screening procedure to detect diabetes among pregnant women [16]. Nor is there a common agreement for which cut off level to define GDM [17]. In Sweden only a few regions have performed OGTT screening during the last ten years and still many regions do not have a general screening programme. Therefore the overall reported frequency of gestational diabetes in The Swedish Medical Birth Register (SMBR) has been and still is very low.

Our assumption is that many women with GDM or IGT (Impaired Glucose Tolerance) have remained undetected during pregnancy and a large proportion of these women will develop diabetes later in life. The aim of this study was to assess if women, who later in life were diagnosed with diabetes, had hyperglycaemia associated complications during their previous pregnancies and deliveries.

\section{Methods}

Women $(n=23,524)$ in the ages 45 - 85 yr, gathered as a population based cohort in Southern Sweden, to study risk factors for malignant melanoma [18], filled a questionnaires in 2000 with information regarding social status, previous illnesses, medication, life habits, diseases and medication. Of these women 808 (3.4\%) declared that they had diabetes mellitus. The data file was matched towards the Swedish Medical Birth Register (SMBR), we recovered 14,856 women who occurred in both registers and these women had 30,559 deliveries registered in SMBR. SMBR started in 1973, includes approximately 100,000 births per year in Sweden and the dropout rate in this register is only $0.5 \%-3 \%$. The register contains data concerning maternal characteristics during pregnancy, delivery and postnatal data regarding the infant. In SMBR diabetes could be registred as "gestational diabetes" or as "diabetes as a concomitant disease". This enabled us to retrospectively study the pregnancies and 
deliveries in relation to if the women had diabetes during pregnancy, developed diabetes later in life or did not develop diabetes during observation time.

The 14,583 women were divided into three different groups: In the first group of women who had "concomitant diabetes" (not gestational diabetes) registered during pregnancy and also had diabetes at the follow up questionnaire were regarded to have Type 1 diabetes $(n=45)$. These women gave birth to 81 newborns registred in SMBR. In the second group we included women who reported diabetes in the follow-up questionnaire in the cohort study and did not had diabetes as a concomitant disease in SMBR $(n=216)$. These women were regarded to have Type 2 diabetes. Women who were registered in SMBR to have GDM during any of their pregnancies (n $=12$ ) were also included in this group. This group therefore includes women both with GDM and/or later onset Type 2 diabetes $(n=228)$. All 455 registered pregnacies belonging to these women are considered to be newborns to women with GDM/Type 2 diabetes. In the last group we included women without diabetes reported at any time $(n=14,583)$. The number of registered deliveries in these women was 30,023.

The median follow-up time after pregnancy was 16 years (range 0 - 27 years). From the SMBR we collected information regarding, maternal weight at first visit during pregnancy, weight-gain during pregnancy (registered in SMBR 1982-1989 and thereafter as a calculated value from weight at delivery minus weight at the beginning of pregnancy), smoking habits, vaginal or instrumental delivery, postnatal complications (death, malformations, resuscitation), birth weight of the infant and Apgar score at 1, 5 and 10 minutes. The Apgar score was rating skin colour, pulse rate, irritability, muscle tone and breathing. Maximum score was 10 and a low Apgar score indicated that the neonate needed medical attention. The frequency of reported Apgar scores was high for 1 and 5 minutes (98.5\% and $91.0 \%$ respectively) but for 10 minutes only reported in $60.1 \%$ of the cases.

The infants were characterized as macrosomic if they had a birth weight $\geq 4500 \mathrm{~g}$, while LGA was retrieved from data reported to the SMBR.

The study was approved by the Ethical Board at Lund University and done in accordance to the recommendation of the Declaration of Helsinki.

Statistical analyses were performed using the SPSS version 17.0 statistical software for PC, (SPSS Inc., Chicago, Illinois). Mean and standard deviations are reported for continuous variables such as weight, weight gain, BMI and birth weight of the infant. Median and range are reported for non-parametric variables such as gestational age and Apgar score. Frequencies in percent are reported for categorical variables such as smoking, caesarean section and instrumental delivery. For comparison between the different groups, Student t-test (age, weight, weight gain, BMI, weight of the infant) and Mann Whitney U-test (gestational week, Apgar score) were used. For comparison of frequencies (caesarean section, LGA, malformations and early infant death) Chi 2 test was performed. For calculation of correlation between weight and weight gain, Pearson's correlation (bivariate) was used. p-values $<0.05$ were considered significant. Multivariate risk factor analyses for low Apgar score, Caesarean section and macrosomia were done using a binary logistic regression in different models including possible risk factors as diabetes, weight of the mother, weight gain during pregnancy, age of the mother and gestational length and smoking in different models.

\section{Results}

The reported frequency of diabetes as a concomitant disease among the women was $0.3 \%(45 / 14,583)$, the frequency of reported GDM among all pregnancies was $0.04 \%(12 / 30,599)$, the frequency of self reported diabetes of both Type 1 and Type 2 in the ages 45 - 85 yr was 1.8\% (261/14,583) and later onset diabetes had a frequency of $1.5 \%(216 / 14,583)$.

Women with Type 1 diabetes $(n=45)$, GDM/Type 2 diabetes $(n=228)$ and no diabetes $(n=14,583)$ did not differ regarding age at the first pregnancy. The women with Type 1 diabetes had lower parity, but there was no significant difference in parity between women with GDM/Type 2 diabetes and women without diabetes. There was no significant difference in the number of smokers in the different groups (Table 1).

Weight gain with a corresponding weight at beginning of pregnancy was found in 10,130 pregnancies (33\%). Regarding the weight of the mothers, we observed significant higher pre-pregnancy weight and BMI among the women with GDM/Type 2 diabetes compared to the women without diabetes. We also observed a significantly lower weight gain during pregnancy in the group of women with GDM/Type 2 diabetes (Table 2). The weight gain was inversely correlated to the pre-pregnancy weight in this group of women $(r=-0.34 ; p<0.001)$. For the other two groups the weight gain was independent of the prepregnancy weight of the mother. 
Table 1. Description of different groups of pregnant women.

\begin{tabular}{|c|c|c|c|c|c|}
\hline & Type 1 diabetes (A) & $\begin{array}{c}\text { GDM or later } \\
\text { Type } 2 \text { diabetes (B) }\end{array}$ & Non-diabetes (C) & $\begin{array}{l}\text { p-Value } \\
\text { (A and C) }\end{array}$ & $\begin{array}{l}\text { p-Value } \\
\text { (B and C) }\end{array}$ \\
\hline Number of women & 45 & 228 & 14,583 & NT & NT \\
\hline Number of newborns & 81 & 455 & 30,023 & NT & NT \\
\hline Age at first pregnancy (yr) & $26.9 ; n=46$ & $26.7 ; n=171$ & $26.9 ; n=13,079$ & $\mathrm{p}=\mathrm{NS}$ & $\mathrm{p}=\mathrm{NS}$ \\
\hline Parity & $1.8 \pm 0.8$ & $2.0 \pm 1.1$ & $2.1 \pm 1.0$ & $\mathrm{p}=0.04$ & $\mathrm{p}=\mathrm{NS}$ \\
\hline Smoking during pregnancy (\%) & $7.4 ; n=6$ & $13.2 ; n=60$ & $12.1 ; n=3641$ & NS & NS \\
\hline $\begin{array}{l}\text { Mean weight at beginning } \\
\text { of pregnancy }(\mathrm{kg})\end{array}$ & $67.2 \pm 13.0 ; n=44$ & $69.2 \pm 13.9 ; n=170$ & $63.2 \pm 10.4 ; n=13,394$ & $\mathrm{p}=0.01$ & $\mathrm{p}<0.001$ \\
\hline Mean BMI $\left(\mathrm{kg} / \mathrm{m}^{2}\right)$ & $24.2 \pm 4.5 ; n=41$ & $25.2 \pm 5.1 ; n=166$ & $22.7 \pm 3.4 ; n=12,874$ & $\mathrm{p}=0.003$ & $\mathrm{p}<0.001$ \\
\hline
\end{tabular}

GDM = Gestational Diabetes Mellitus; BMI = Body Mass Index; NT = Not Tested; NS = Not Significant.

Table 2. Characteristics of pregnancies in different groups of women.

\begin{tabular}{cccccc}
\hline & $\begin{array}{c}\text { Type 1 } \\
\text { diabetes (A) }\end{array}$ & $\begin{array}{c}\text { GDM or later Type 2 } \\
\text { diabetes (B) }\end{array}$ & $\begin{array}{c}\text { Non-diabetes } \\
\text { (C) }\end{array}$ & $\begin{array}{c}\text { p-Value } \\
\text { (A and C) }\end{array}$ & $\begin{array}{c}\text { p-Value } \\
(\mathrm{B} \text { and C) }\end{array}$ \\
\hline Mean weight gain (kg) & $14.1 \pm 6.1$ & $13.3 \pm 5.4$ & $14.1 \pm 4.7$ & NS & 0.03 \\
Gestational length (weeks) & 39.1 & 39.9 & 40.1 & $<0.001$ & 0.001 \\
Macrosomia n; (\%) & $20 / 61 ;(24.7)$ & $127 / 327 ;(28.0)$ & $5437 / 24522 ;(18.1)$ & NS & $<0.001$ \\
Frequency of Caesarean sections n (\%) & $6(7.4)$ & $22(4.8)$ & $808(2.7)$ & 0.009 & 0.005 \\
Frequency of vacuum forceps n (\%) & $2(2.5)$ & $10(2.2)$ & $397(1.3)$ & NS & NS \\
\hline
\end{tabular}

GDM = Gestational Diabetes Mellitus; NS = Not Significant.

The median gestational age in weeks differed significantly. The women with GDM/Type 2 diabetes had a shorter gestational length than women without diabetes (39.9; quartile 38.6 - 41.0 weeks vs. 40.1; quartile 39.1 41.1; $\mathrm{p}=0.001$ ). Despite the shorter gestational length the mean weight of the infants of the mothers with GDM/Type 2 diabetes was significantly higher than the infants of the mothers without diabetes $(3602 \mathrm{~g} \pm 680 \mathrm{~g}$ vs. $3507 \mathrm{~g} \pm 579 \mathrm{~g} ; \mathrm{p}=0.001$ ). The mean weight of the infants of women with Type 1 diabetes (3541 $\pm 720 \mathrm{~g} ; \mathrm{p}$ $=$ ns) did not significantly differ from the infants of the mothers without diabetes. The total number of registered LGA-infants in our study was $\mathrm{n}=956(3 \%)$ while the number of macrosomic infants, by our definition was 5584 (18.3\%). The frequencies of LGA and macrosomic infants were both significantly higher in the group of women with GDM/Type 2 diabetes (Figure 1, Table 1).

The frequency of caesarean section was significantly higher both in women with Type 1 diabetes and women with GDM/Type 2 diabetes compared to women without diabetes. There was no difference in the number of vacuum extractions (VE) or forceps-deliveries (Table 1).

The median Apgar scores at 1, 5 and 10 minutes were significantly lower in GDM/Type 2 diabetes deliveries compared to deliveries without diabetes ( $p=0.001, p=0.002$ and $p=0.001$, respectively). Only $84.6 \%$ of the infants of the women with GDM/Type 2 diabetes had Apgar score of 10 after 10 minutes, compared to $90.7 \%$ in the non-diabetes group (Figure 2).

There was no detectable difference in frequency of malformations in the infants in the different groups, since it was $6.2 \%(n=5)$ for Type 1 diabetes, $6.4 \%(n=29)$ for GDM/Type 2 diabetes and $5.1 \%(n=1530)$ in pregnancies in women without diabetes $(\mathrm{p}=\mathrm{ns})$. There was also no difference between the frequencies of early infant deaths (before 28 days of age) between the different groups $(1.2 \%, 0.9 \%$ and $0.4 \%$ respectively; $\mathrm{p}=\mathrm{ns})$.

\section{Discussion}

Women diagnosed with diabetes after pregnancy, differed already during these pregnancies in several parameters. The mothers were heavier, gained less weight during pregnancy, had more complications during delivery 


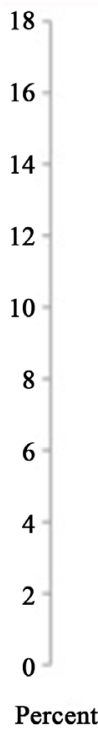

16

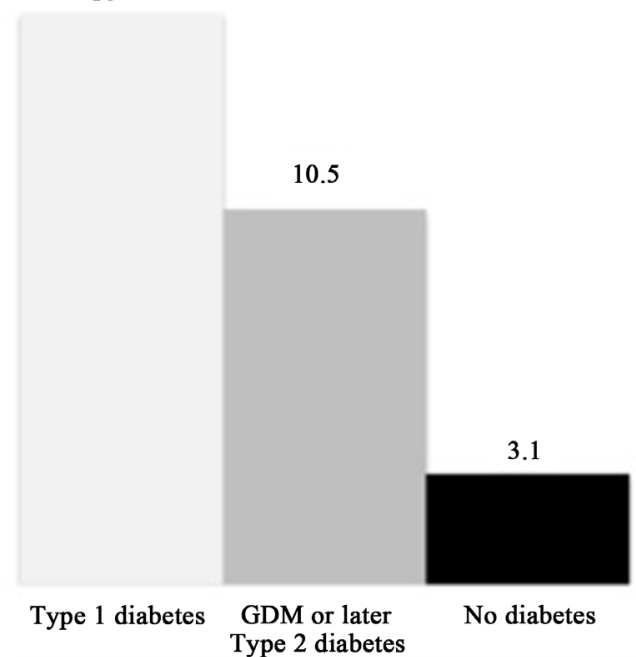

Figure 1. The frequency of newborns who were large for gestational age (LGA) born to women with concomitant Type 1 diabetes $(n=81)$ was $16 \%$ which was higher than the frequency in newborns to women reported to have gestational diabetes mellitus (GDM) or later in life developed Type 2 diabetes $(n=440 ; p<0.001)$ where is was $10.5 \%$. Both groups had significantly higher frequencies of LGA compared to women without diabetes $(n=29,234 ; p<0.001)$ who had 3.1\% LGA.

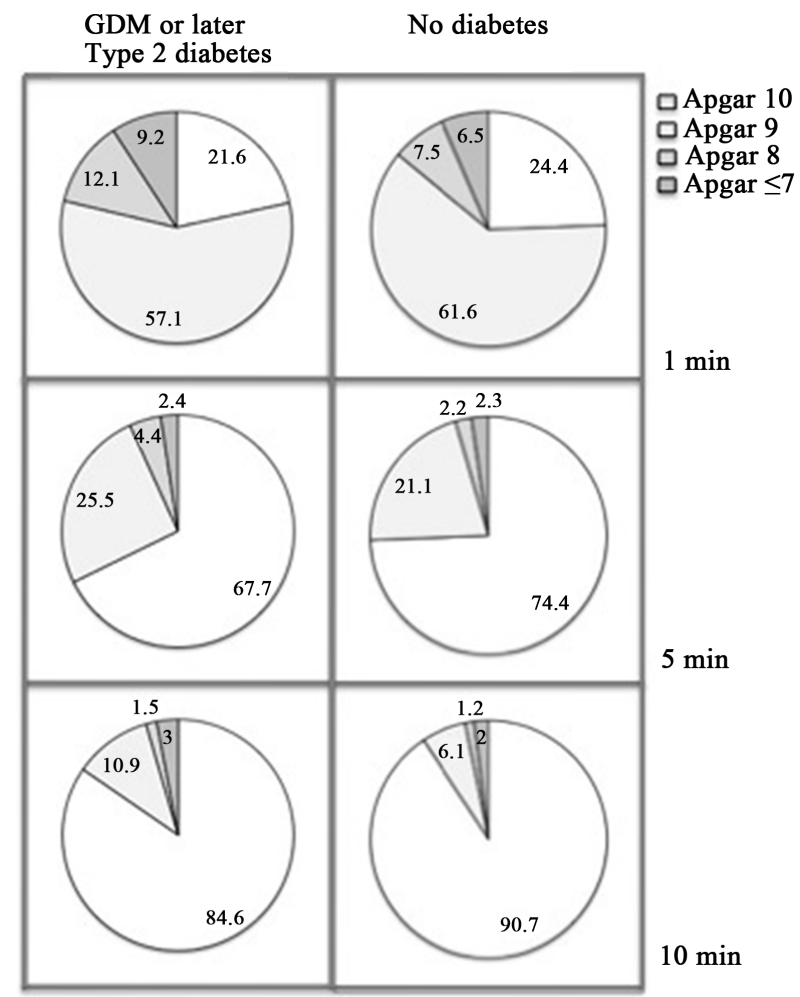

Figure 2. The distribution of Apgar score into four groups (10, 9, 8 and $<7)$ after 1, 5 and 10 minutes, in newborns to women with reported gestational diabetes mellitus (GDM) during pregnancy or later in life developed diabetes compared to newborns to women with no diabetes ever reported, showed for all time points measured lower scores for newborns to women with diabetes $(p<0.001, p<0.002$ and $p<0.001)$. 
and were more often delivered by caesarean section compared to women who did not develop diabetes later in life. Their newborns were heavier despite a shorter gestational length and had significantly lower Apgar scores.

In this retrospective study of a large cohort of women from southern Sweden we noticed that the reported frequency of concomitant diabetes during pregnancy was $(n=45 ; 0.3 \%)$ which is a frequency that corresponds to the expected frequency of Type 1 diabetes in the female population in these ages in Sweden. The reported frequency of $0.04 \%$ GDM pregnancies was however much lower than the expected number of 367 - 580 based on a frequency of $1.2 \%-1.9 \%$ GDM pregnancies obtained at our hospital after 1995 when general screening with OGTT was initiated [6] [7]. With a parity of two children/mothers the expected number of women with GDM would be about 180 - 290. A follow up study in Denmark, has shown an incidence of abnormal glucose tolerance in about 70\% of women with previous GDM seven years after pregnancy [3]. In our region 31\% of the women had an abnormal glucose metabolism one year after delivery [1]. It is therefore reasonable to assume that a majority of the 216 women in our cohort who developed Type 2 diabetes during the long follow-up time of median 16 years after pregnancy have had a previous undiagnosed GDM. The major weakness of our study is that we do not have any p-glucose value taken from these women to confirm a previous GDM diagnosis. The strength of the study is that these women were unaware of any hyperglycemia and therefore not object for any intervention that could give a bias to the study. The design of this study therefore enables us to retrospectively study the natural course and outcome of these pregnancies with a presumed disturbance in glucose metabolism.

Women reported to have concomitant diabetes and assumed to have Type 1 diabetes, had as lower parity and significant higher body weight than women without diabetes but lower than those with GDM or later Type 2 diabetes. They had shorter gestational length, were more often delivered by Caesarean section but there were no difference regarding birth weight.

Women in our study with GDM or later Type 2 diabetes, had a higher prepregnancy BMI that was correlated to the birth weight of the infants and in agreement with studies showing that high maternal BMI caused a high infant birth weight [19] [20]. However, the lower weight gain of the mother (Table 1) was opposite to the findings in a Swedish study showing that a low pregnancy weight gain reduces the risk of giving birth to a LGA-infant irrespective of prepregnancy BMI, but this was shown in a population without diabetes [21]. A study in Sweden found that women with untreated IGT during pregnancy had more LGA infants [22]. A similar frequency of LGA-births as we found were found in women treated for GDM supporting the assumption that many of these women who later developed Type 2 diabetes in our study have had undiagnosed GDM [23]. Differences in gestational length could not explain the higher weight of the infants, since gestational length among these women in our study was significantly shorter compared to women without diabetes (Table 1).

In multivariate analyses, GDM or later diagnosis of Type 2 diabetes was a risk factor associated with macrosomia, Caesarean section as well as low Apgar scores. In the group of women with GDM or later Type 2 diabetes, only 12/228 (4\%) had GDM reported and it is therefore unlikely to believe that the observed shorter gestational length or increased frequency of Caesarean section were results of active intervention. The higher frequency of caesarean section among the women with later Type 2 diabetes may be due to larger infants or preeclampsia, which both are known complications associated with GDM. However, in the regression analysis including the whole population studied, it was low more than high birth weight that was associated with a higher frequency of caesarean section (Table 2). The regression analysis, therefore only showed small but significant increased risk of caesarean section in the women who later developed diabetes (Table 2, Model III). Regression analysis is not the best method to estimate the negative influence of GDM on pregnancy outcome due to the relatively low frequency of GDM compared to prematurity for other reasons. Prematurity is associated with low birth weight and GDM with high which create an U-shaped risk curve for birth weight. Treatment of hyperglycaemia during pregnancy does not always reduce the risk of caesarean section [13]. The highest frequency of caesarean section was found in women assumed to have Type 1 diabetes. Their gestational length was in average one week shorter indicating that some of these pregnancies were terminated by a Caesarean section probably since Type 1 diabetes in the mother was a known complicating factor.

Apgar scores are used as an indicator of the well being of the newborn. The Apgar scores of the infants were lower among the women with GDM or later Type 2 diabetes compared to women without diabetes. In the multivariate analysis calculating risk for low Apgar scores in the whole cohort, prepregnancy weight of the mother, GDM or later Type 2 diabetes, low birth weight and short gestational length were significant risk factors at 5 min but for low Apgar at 10 min only low birth weight and short gestational length remained (Table 3). This indicates that prematurity of any reason in general is the dominating condition behind sustained low Apgar score. 
Table 3. Odds ratios (OR) for different adverse outcomes of pregnancies such as Caesarean section, Apgar score less than 8 and macrosomic newborn respectively in different models including different risk factors.

\begin{tabular}{|c|c|c|c|c|}
\hline & Variable & OR & $95 \% \mathrm{CI}$ & p-Value \\
\hline \multicolumn{5}{|c|}{ Caesarean Section } \\
\hline \multirow[t]{6}{*}{ Model I; n = 9633} & Prepregnancy BMI & 1.16 & $1.10-1.22$ & $<0.001$ \\
\hline & Maternal age (yr) & 1.12 & $1.08-1.16$ & $<0.001$ \\
\hline & GDM or later Type 2 diabetes & 1.02 & $0.30-3.54$ & NS \\
\hline & Weight gain (kg) & 1.01 & $0.97-1.05$ & NS \\
\hline & Birth weight (hg) & 0.97 & $0.93-1.00$ & NS \\
\hline & Gestational length (weeks) & 0.88 & $0.79-0.99$ & 0.03 \\
\hline \multirow[t]{4}{*}{ Model II; n = 30,368 } & GDM or later Type 2 diabetes & 1.48 & $0.94-2.34$ & NS \\
\hline & Maternal age (yr) & 1.20 & $1.18-1.21$ & $<0.001$ \\
\hline & Gestational length (weeks) & 0.81 & $0.77-0.84$ & $<0.001$ \\
\hline & Birth weight (hg) & 0.99 & $0.97-1.00$ & NS \\
\hline \multirow[t]{5}{*}{ Model III; n = 13,000 } & GDM or later Type 2 diabetes & 1.81 & $1.01-3.24$ & 0.048 \\
\hline & Maternal age (yr) & 1.20 & $1.18-1.22$ & $<0.001$ \\
\hline & Prepregnancy BMI & 1.02 & $1.01-1.03$ & 0.001 \\
\hline & Birth weight (hg) & 0.98 & $0.96-1.00$ & 0.054 \\
\hline & Gestational length (weeks) & 0.79 & $0.75-0.83$ & $<0.001$ \\
\hline \multicolumn{5}{|c|}{ Low Apgar Score $(<8)$} \\
\hline \multirow[t]{5}{*}{1 minute; $n=12,255$} & GDM or later Type 2 diabetes & 1.70 & $1.17-2.48$ & 0.006 \\
\hline & Prepregnancy BMI & 1.04 & $1.03-1.06$ & $<0.001$ \\
\hline & Birth weight (hg) & 0.98 & $0.97-0.99$ & 0.001 \\
\hline & Gestational length (weeks) & 0.93 & $0.90-0.97$ & $<0.001$ \\
\hline & Smoking & 1.02 & $0.90-1.15$ & NS \\
\hline \multirow[t]{5}{*}{5 minutes; $\mathrm{n}=12,197$} & GDM or later Type 2 diabetes & 1.93 & $1.04-3.60$ & 0.03 \\
\hline & Prepregnancy BMI & 1.04 & $1.01-1.07$ & 0.003 \\
\hline & Birth weight (hg) & 0.94 & $0.92-0.96$ & $<0.001$ \\
\hline & Gestational length (weeks) & 0.90 & $0.85-0.96$ & $<0.001$ \\
\hline & Smoking & 1.02 & $0.82-1.28$ & NS \\
\hline \multirow[t]{5}{*}{10 minutes; $\mathrm{n}=10,069$} & GDM or later Type 2 diabetes & 1.70 & $0.61-4.74$ & NS \\
\hline & Prepregnancy BMI & 1.02 & $0.98-1.07$ & NS \\
\hline & Birth weight (hg) & 0.97 & $0.93-1.00$ & 0.05 \\
\hline & Gestational length (weeks) & 0.83 & $0.76-0.91$ & $<0.001$ \\
\hline & Smoking & 0.84 & $0.57-1.23$ & NS \\
\hline \multicolumn{5}{|c|}{ Macrosomia } \\
\hline \multirow[t]{5}{*}{ Model I; n = 9444} & GDM or later Type 2 diabetes & 2.10 & $1.32-3.35$ & 0.002 \\
\hline & Gestational length (weeks) & 1.78 & $1.70-1.87$ & $<0.001$ \\
\hline & Weight gain (kg) & 1.09 & $1.08-1.11$ & $<0.001$ \\
\hline & Prepregnancy weight (kg) & 1.05 & $1.05-1.06$ & $<0.001$ \\
\hline & Mother's age (yr) & 1.03 & $1.02-1.04$ & $<0.001$ \\
\hline
\end{tabular}

GDM = Gestational Diabetes Mellitus; BMI = Body Mass Index; OR = Odds Ratio; CI = Confidence Interval; NS = Not Significant. 
In addition to the delivery complications caused by hyperglycemia there are also an increasing focus on long term complications due to GDM. The development of Type 2 diabetes later in life is the main threat to the women with previous GDM pregnancies. Despite the known high risk in this group, a recent study showed that many women still do not have any follow up after a pregnancy with GDM [24] [25]. For the offspring there is a substantial risk for obesity starting already before puberty [26]-[28]. The mechanism behind the transfer of the metabolic syndrome from mother to child is unclear. The impact of hyperglycemia in utero has been claimed [28]. We have found that siblings born after a non-diabetes pregnancy have the same risk for obesity as siblings born after a GDM pregnancy, supporting life style influence [26]. Results from several recent life style intervention studies in women with GDM pregnancies showed promising results [29] [30]. It is therefore of importance to identify these women early in life to promote a healthy life style program.

In conclusion, we assume that a majority of women developing diabetes later in life had previous outcomes of pregnancies that could be due to disturbed glucose metabolism. Hyperglycaemia during pregnancy should be treated for better delivery outcome and with the intention to reduce the future risk for diabetes and obesity both in the women and in their children.

\section{Acknowledgements}

Research Funds in Region Skane and Funds at the University Hospital in Lund and ALF-founding, Lund University have contributed to this study.

\section{References}

[1] Åberg, A.E.B., Jönsson, E.K., Eskilsson, I., Landin-Olsson, M. and Frid, A.H. (2002) Predictive Factors of Developing Diabetes Mellitus in Women with Gestational Diabetes. Acta Obstetricia et Gynecologica Scandinavica, 81, 11-16. http://dx.doi.org/10.1046/j.0001-6349.2001.00000.x

[2] Feig, D.S., Zinman, B., Wang, X. and Hux, J.E. (2008) Risk of Development of Diabetes Mellitus after Diagnosis of Gestational Diabetes. CMAJ, 179, 229-234. http://dx.doi.org/10.1503/cmaj.080012

[3] Damm, P. (2009) Future Risk of Diabetes in Mother and Child after Gestational Diabetes Mellitus. International Journal of Gynecology Obstetrics, 104, S25-S26. http://dx.doi.org/10.1016/j.ijgo.2008.11.025

[4] Pedersen, J. (1952) Course of Diabetes during Pregnancy. Acta Endocrinology, 9, 342-364.

[5] Wood, S.L., Jick, H. and Sauve, R. (2003) The Risk of Stillbirth in Pregnancies before and after the Onset of Diabetes. Diabetic Medicine, 20, 703-707. http://dx.doi.org/10.1046/j.1464-5491.2003.01015.x

[6] Åberg, A., Rydhström, H. and Frid, A. (2001) Impaired Glucose Tolerance Associated with Adverse Pregnancy Outcome: A Population-Based Study in Southern Sweden. American Journal of Obstetrics Gynecology, 184, 77-83. http://dx.doi.org/10.1067/mob.2001.108085

[7] Anderberg, E., Källén, K., Berntorp, K., Frid, A. and Aberg, A. (2007) A Simplified Oral Glucose Tolerance Test in Pregnancy: Compliance and Results. Acta Obstetricia et Gynecologica Scandinavica, 86, 1432-1436. http://dx.doi.org/10.1080/00016340701532444

[8] Anderberg, E., Källén, K. and Berntorp, K. (2010) The Impact of Gestational Diabetes Mellitus on Pregnancy Outcome Comparing Different Cut-Off Criteria for Abnormal Glucose Tolerance. Acta Obstetricia et Gynecologica Scandinavica, 89, 1532-1537. http://dx.doi.org/10.3109/00016349.2010.526186

[9] Weinert, L.S. (2010) International Association of Diabetes and Pregnancy Study Groups Recommendations on the Diagnosis and Classification of Hyperglycemia in Pregnancy: Comment to the International Association of Diabetes and Pregnancy Study Groups Consensus Panel. Diabetes Care, 33, e97-e98. http://dx.doi.org/10.2337/dc10-0544

[10] Jensen, D.M., Korsholm, L., Ovesen, P., Beck-Nielsen, H., Mølsted-Pedersen, L. and Damm, P. (2008) Adverse Pregnancy Outcome in Women with Mild Glucose Intolerance: Is There a Clinically Meaningful Threshold Value for Glucose? Acta Obstetricia et Gynecologica Scandinavica, 87, 59-62. http://dx.doi.org/10.1080/00016340701823975

[11] Metzger, B.E., Lowe, L.P., Dyer, A.R., Trimble, E.R., Chaovarindr, U., et al., HAPO Study Cooperative Research Group (2008) Hyperglycemia and Adverse Pregnancy Outcomes. The New England Journal of Medicine, 358, 19912002. http://dx.doi.org/10.1056/NEJMoa0707943

[12] HAPO Study Cooperative Research Group (2009) Hyperglycemia and Adverse Pregnancy Outcome (HAPO) Study: Associations with Neonatal Anthropometrics. Diabetes, 58, 453-459. http://dx.doi.org/10.2337/db08-1112

[13] Crowther, C.A., Hiller, J.E., Moss, J.R., McPhee, A.J., Jeffries, W.S., Robinson, J.S., et al. (2005) Effect of Treatment of Gestational Diabetes Mellitus on Pregnancy Outcomes. The New England Journal of Medicine, 352, 2477-2486. http://dx.doi.org/10.1056/NEJMoa042973 
[14] Landon, M.B., Spong, C.Y., Thom, E., Carpenter, M.W., Ramin, S.M., Casey, B., et al. (2009) A Multicenter, Randomized Trial of Treatment for Mild Gestational Diabetes. The New England Journal of Medicine, 361, 1339-1348. http://dx.doi.org/10.1056/NEJMoa0902430

[15] Horvath, K., Koch, K., Jeitler, K., Matyas, E., Bender, R., Bastian, H., et al. (2010) Effects of Treatment in Women with Gestational Diabetes Mellitus: Systematic Review and Meta-Analysis. BMJ, 340, c1395. http://dx.doi.org/10.1136/bmj.c1395

[16] Buckley, B.S., Harreiter, J., Damm, P., Corcoy, R., Chico, A., Simmons, D., et al. (2012) Gestational Diabetes Mellitus in Europe: Prevalence, Current Screening Practice and Barriers to Screening. A Review. Diabetic Medicine, 29, 844854. http://dx.doi.org/10.1111/j.1464-5491.2011.03541.x

[17] Hartling, L., Dryden, D.M., Guthrie, A., Muise, M., Vandermeer, B. and Donovan, L. (2014) Diagnostic Thresholds for Gestational Diabetes and Their Impact on Pregnancy Outcomes: A Systematic Review. Diabetic Medicine, 31, 319331. http://dx.doi.org/10.1111/dme.12357

[18] Lindqvist, P.G., Olsson, H. and Landin-Olsson, M. (2010) Are Active Sun Exposure Habits Related to Lowering Risk of Type 2 Diabetes Mellitus in Women, a Prospective Cohort Study? Diabetes Research and Clinical Practice, 90, 109-114. http://dx.doi.org/10.1016/j.diabres.2010.06.007

[19] HAPO Study Cooperative Research Group (2010) Hyperglycaemia and Adverse Pregnancy Outcome (HAPO) Study: Associations with Maternal Body Mass Index. BJOG, 117, 575-584. http://dx.doi.org/10.1111/j.1471-0528.2009.02486.x

[20] Wikström, I., Axelsson, O. and Bergström, R. (1991) Maternal Factors Associated with High Birth Weight. Acta Obstetricia et Gynecologica Scandinavica, 70, 55-61. http://dx.doi.org/10.3109/00016349109006179

[21] Cedergren, M. (2006) Effects of Gestational Weight Gain and Body Mass Index on Obstetric Outcome in Sweden. International Journal of Gynecology Obstetrics, 93, 269-274. http://dx.doi.org/10.1016/j.ijgo.2006.03.002

[22] Ostlund, I., Hanson, U., Björklund, A., Hjertberg, R., Eva, N., Nordlander, E., et al. (2003) Maternal and Fetal Outcomes If Gestational Impaired Glucose Tolerance Is Not Treated. Diabetes Care, 26, 2107-2111. http://dx.doi.org/10.2337/diacare.26.7.2107

[23] Fadl, H.E., Ostlund, I.K.M., Magnuson, A.F.K. and Hanson, U.S.B. (2010) Maternal and Neonatal Outcomes and Time Trends of Gestational Diabetes Mellitus in Sweden from 1991 to 2003. Diabetic Medicine, 27, 436-441. http://dx.doi.org/10.1111/j.1464-5491.2010.02978.x

[24] Tovar, A., Chasan-Taber, L., Eggleston, E. and Oken, E. (2011) Postpartum Screening for Diabetes among Women with a History of Gestational Diabetes Mellitus. Preventing Chronic Disease, 8, A124.

[25] Bihan, H., Cosson, E., Khiter, C., Vittaz, L., Faghfouri, F., Leboeuf, D., et al. (2014) Factors Associated with Screening for Glucose Abnormalities after Gestational Diabetes Mellitus: Baseline Cohort of the Interventional IMPACT Study. Diabetes Metabolism, 40, 151-157. http://dx.doi.org/10.1016/j.diabet.2013.12.002

[26] Nilsson, C., Carlsson, A. and Landin-Olsson, M. (2014) Increased Risk for Overweight among Swedish Children Born to Mothers with Gestational Diabetes Mellitus. Pediatric Diabetes, 15, 57-66. http://dx.doi.org/10.1111/pedi.12059

[27] Morgan, K., Rahman, M., Atkinson, M., Zhou, S.-M., Hill, R., Khanom, A., et al. (2013) Association of Diabetes in Pregnancy with Child Weight at Birth, Age 12 Months and 5 Years-A Population-Based Electronic Cohort Study. PLOS ONE, 8, e79803. http://dx.doi.org/10.1371/journal.pone.0079803

[28] Hiersch, L. and Yogev, Y. (2014) Impact of Gestational Hyperglycemia on Maternal and Child Health. Current Opinion in Clinical Nutrition and Metabolic Care, 17, 255-260. http://dx.doi.org/10.1097/MCO.0000000000000030

[29] Ferrara, A. and Ehrlich, S.F. (2011) Strategies for Diabetes Prevention before and after Pregnancy in Women with GDM. Current Diabetes Reviews, 7, 75-83. http://dx.doi.org/10.2174/157339911794940738

[30] Rautio, N., Jokelainen, J., Korpi-Hyövälti, E., Oksa, H., Saaristo, T., Peltonen, M., et al. (2014) Lifestyle Intervention in Prevention of Type 2 Diabetes in Women with and without a History of Gestational Diabetes Mellitus: One-Year Results of the FIN-D2D Project. Journal of Women's Health (Larchmt), 23, 506-512. http://dx.doi.org/10.1089/jwh.2013.4520 
Scientific Research Publishing (SCIRP) is one of the largest Open Access journal publishers. It is currently publishing more than 200 open access, online, peer-reviewed journals covering a wide range of academic disciplines. SCIRP serves the worldwide academic communities and contributes to the progress and application of science with its publication.

Other selected journals from SCIRP are listed as below. Submit your manuscript to us via either submit@scirp.org or Online Submission Portal.
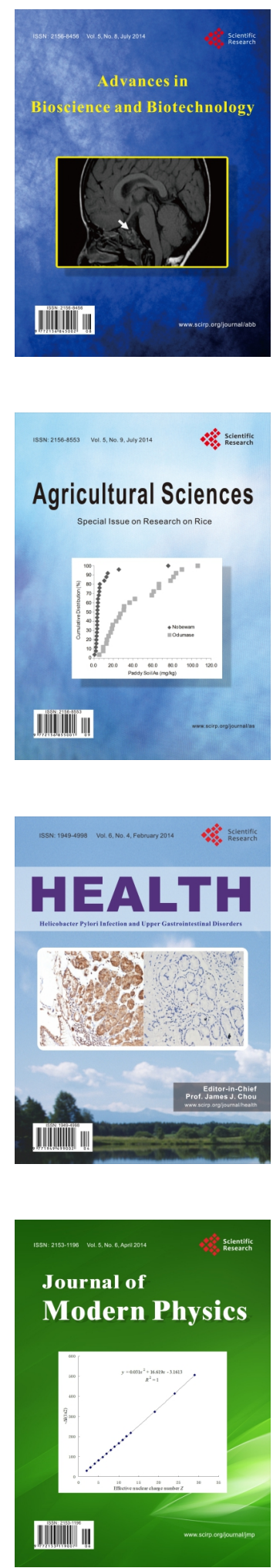
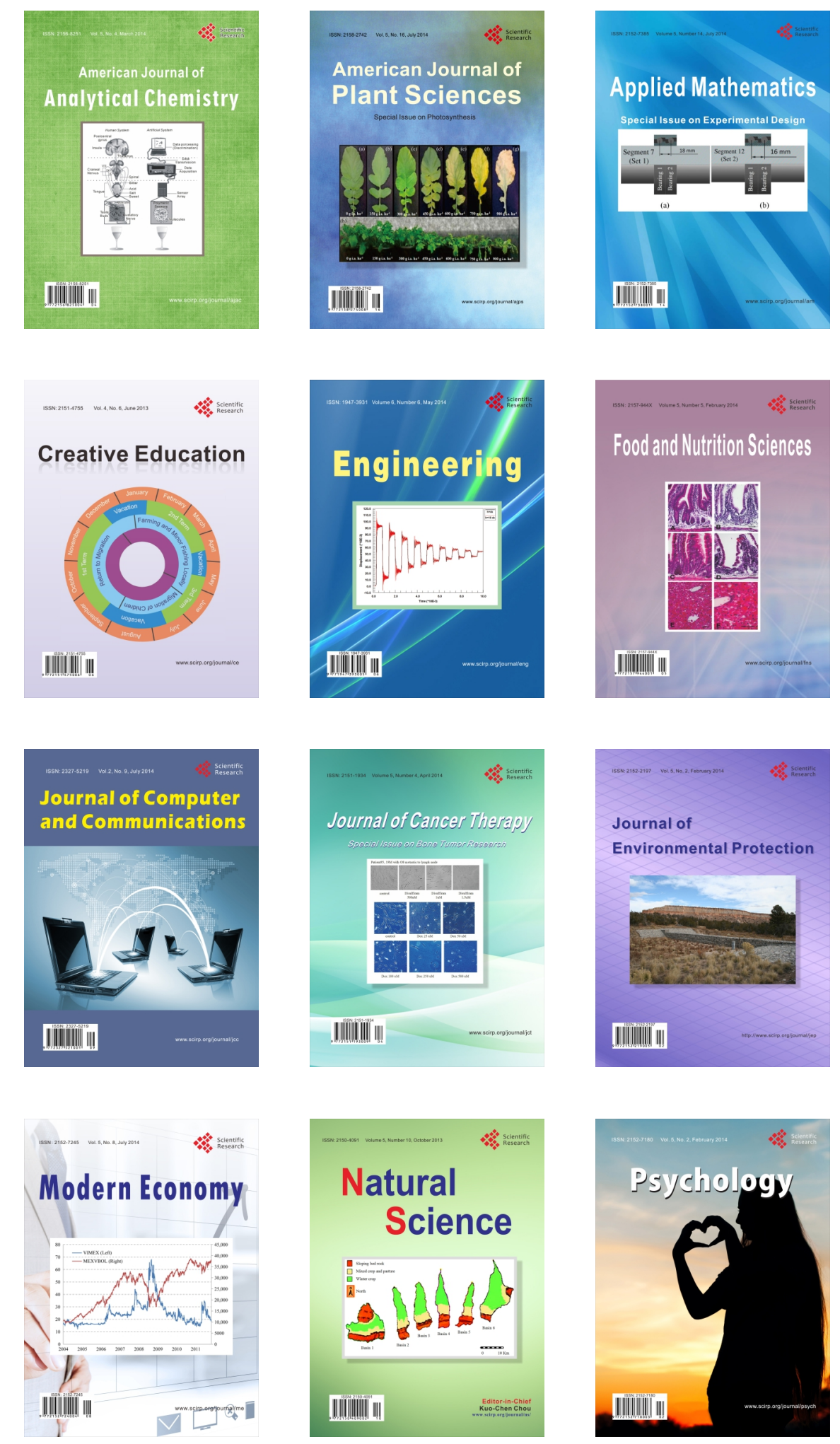